\title{
Infertility and associated factors in three hospitals in Douala, Cameroon: a cross-sectional study
}

\author{
Thomas Obinchemti Egbe ${ }^{1,2}$, Charmaine Ngo Mbaki ${ }^{3}$, Nicholas Tendongfor ${ }^{2}$, \\ Elvis Temfack ${ }^{4}$, Eugene Belley-Priso ${ }^{5}$
}

1. Department of Obstetrics and Gynaecology, Douala General Hospital, Cameroon.

2. Faculty of Health Sciences, University of Buea, Cameroon.

3. Mbingo Baptist Hospital, Mboppi, Douala, Cameroon.

4. Department of Clinical Research and Internal Medicine, Douala General Hospital.

5. Department of Obstetrics and Gynaecology, Faculty of Medicine and Biomedical Sciences, University of Yaoundé, Cameroon.

\begin{abstract}
Aim: We determined the prevalence and factors associated with couple infertility in three hospitals in Douala, Cameroon. Methods: We conducted a cross-sectional study from December 18th 2015 to March 18th

2016 in three public hospitals in Douala. Three hundred and sixty participants were studied prospectively for associated factors using a multivariate logistic regression model and 4732 files were studied retrospectively for the prevalence of infertility. Statistical significance was set at $\mathrm{p}<0.05$.

Results: The prevalence of couple infertility was 19.2\%. In logistic models, the factors which independently increased the risk of couple infertility were a history of reproductive tract infection/STI, a history of uterine fibroids, a history of dysmenorrhea and abortion for the females while for males it was a history of mumps, erectile dysfunction and exposure to chemicals/toxic substances/pesticides.

Conclusion: One in every five couples in this study was infertile. Several factors affect the risks associated with couple infertility. The identification of these factors could help detect subgroups of couples at high risk of infertility. Reproductive health education, screening programmes for STI's that may lead to infertility should be offered to couples.
\end{abstract}

Keywords: Couple infertility; prevalence; associated factors; Douala; Cameroon.

DOI: https://dx.doi.org/10.4314/ahs.v20i4.57

Cite as: Egbe TO, Mbaki CN, Tendongfor N, Temfack E, Belley-Priso E. Infertility and associated factors in three hospitals in Douala, Cameroon: a cross-sectional study. Afri Health Sci. 2020;20(4):1985-95. https:// dx.doi.org/10.4314/abs.v20i4.57

\section{Introduction}

Infertility is a disease of the reproductive system defined as the failure to achieve a clinical pregnancy after twelve months or more of regular unprotected sexual intercourse or due to an impairment of a person's capacity to reproduce, either as an individual or with his/

\section{Corresponding author:}

Thomas Obinchemti Egbe,

Department of Obstetrics and Gynaecology,

Faculty of Health Sciences, University of Buea

Cameroon and Douala General Hospital,

Douala, Cameroon

Tel: + 237662407135

E-mail: toegbe@gmail.com;

obinchemti@yahoo.com her partner ${ }^{1}$. It is a public health problem that affects about $8 \%-12 \%$ of couples worldwide ${ }^{1}$. Infertility is further categorized as primary or secondary. The primary infertile female is a woman who has never been diagnosed with a clinical pregnancy and meets the criteria of being classified as having infertility. Secondary female infertility applies to a woman unable to establish a clinical pregnancy but who has previously been diagnosed with a clinical pregnancy ${ }^{2}$. Secondary infertility is the most common form of female infertility worldwide especially in regions like sub-Saharan Africa where there are high rates of unsafe abortions, poor maternity care leading to post-abortive and postpartum infections 3,4 . Besides, there has been a fertility decline in Asia, Latin America and the developed world but Africa has noticed little reproductive changes during the same periods ${ }^{5}$. Infertility affects about $10 \%$ to $30 \%$ of couples 
in sub-Saharan Africa ${ }^{6}$. Furthermore, women were responsible for $25 \%-37 \%$ of infertility in Africa ${ }^{7}$ although Sule et al., reported that female infertility accounted for $51.5 \%$ of patients admitted to the gynaecology departments of four hospitals in Osun State Nigeria, over a two-year- period $^{8}$. Also, Abubakar et al. in 2011 reported a prevalence of infertility of $15.7 \%$ in a teaching hospital in Sokoto, Nigeria ${ }^{\text {? }}$

More than $90 \%$ of male infertility results from low sperm count (oligospermia), poor sperm quality (teratozoospermia), or both. The factors associated with couple infertility are hypogonadotropic hypogonadism, hyperprolactinaemia, disorders of ciliary function, cystic fibrosis, infections, systemic diseases and lifestyle-related factors/diseases ${ }^{10-13}$. Premature ovarian insufficiency, polycystic ovary syndrome, endometriosis, uterine fibroids and endometrial polyps may play a role in female infertility ${ }^{12,13}$. Male infertility may be due to testicular and post-testicular deficiencies ${ }^{14-16}$. Semen decline that has been observed over the last 50 years, endocrine-disrupting chemicals and consanguinity are other factors that may be involved ${ }^{17-21,22}$.

In Cameroon, issues relating to reproductive health are usually geared towards contraception and family planning. Policy makers have so far not taken infertility and related problems sufficiently seriously. There is paucity of data on the prevalence and associated factors of infertility in Cameroon. Moreover, the causes of infertility are multifactorial and any gender could be at the origin of infertility. However, in Cameroon, the female gender bears much of the blame for this problem. The men, on the other hand, cling to traditional practices to protect their ego and do not recognize infertility as a medical condition. Socio-cultural perceptions and beliefs among African people still predominate in our setting. Consequently, establishing the burden of infertility and identifying the associated factors is fundamental in understanding and demystifying this health problem. Infertility, unlike other medical conditions, involves both partners and several dynamic associated factors. Identifying the aetiologies and associated factors in our society will, therefore, be beneficial to health care providers in establishing a diagnosis to institute appropriate management.

Parenthood is an important achievement for married couples in our society. It is customary for the families of the couple to expect the announcement of an expected baby within less than a year of marriage. However, not all couples that desire a pregnancy will achieve one spontaneously and a proportion of the couples would need medical assistance to resolve the underlying fertility problems.

Due to the misconception and ignorance of the general population about this condition, there is need for replacement of traditional beliefs with scientific facts thus making such studies essential.

Data on infertility in our society is lacking. As such, providing data on the prevalence and associated factors of infertility in Cameroon would inform clinicians and health policy makers on the severity of this condition, its public health implications and the need for investment of resources in its management. We hypothesize that the burden of couple infertility in Douala is high and that there are several associated factors, especially of infectious origin. This study aimed to determine the prevalence and associated factors of infertility in three hospitals in Douala, Cameroon.

\section{Materials and methods \\ Study design and site}

We conducted a hospital-based cross-sectional study from December $18^{\text {th }} 2015$ to March $18^{\text {th }} 2016$ where data was collected prospectively from participants who came to the OPD of the three public hospitals in Douala. Simultaneously, we studied files of those who consulted at the obstetrics and gynaecology unit of the three hospitals from 2011 to 2015 for the prevalence study. A total of 4732 files were studied, among which 858 had the diagnoses of infertility.

Douala is a metropolitan city and the economic capital of Cameroon with about 3 million inhabitants. The three hospitals studied included a tertiary care centre (the Douala General Hospital, DGH), a secondary care centre (the Douala Laquintinie Hospital DLH) and a primary care centre (the Bonassama District Hospital $\mathrm{BDH})$.

\section{Study population \\ Accessible population}

The target population included couples attending the Obstetrics and Gynaecology units either for infertility related complaints or for obstetrical reasons.

\section{Inclusion criteria}

We enrolled consenting females of reproductive age (15-49 years) and their partners who consulted for infertility related issues during the study period. We also included consenting couples consulting for pregnancy follow up (antenatal care) during the study period, to compare their characteristics with those who were infertile. 


\section{Exclusion criteria}

We excluded women with other gynaecological problems and those who were not in the reproductive age group. We also excluded women who had tried to conceive for less than one year, those who conceived (with difficulty) after infertility or medical treatment, those receiving any form of contraception and women with a history of hysterectomy.

\section{Sampling}

\section{Sampling method and sample size calculation}

Sample sizes were determined for the $95 \%$ confidence interval with a design effect of 1.1 using the Lorenz formula ${ }^{23}$. A hospital-based study carried out by Aubakar et al. 2011 in Sokoto Northwest Nigeria reported that the prevalence of infertility was $15.7 \%{ }^{9}$. With this assumption, a sample size of 203 participants would be required. With a projected subject dropout rate of $10 \%$ the total number of subjects required for study was 223 . Participants were selected consecutively as they reported daily for consultation.

\section{Study procedure \\ Participant enrolment and data collection}

For the prospective phase of the study and after obtaining ethical clearance from the Institutional Ethics Committee for Research on Humans of the University of Douala (Ref. No IEC-UD/462/02/2016/T) and administrative approvals from the Douala General Hospital (Ref No 087AR/MINSANTE/HGD/DM/01/16), the Douala Laquintinie Hospital (Ref. No 48/AR/ MINSANTE/DHL/CM), and the Bonassama District Hospital (Ref. No 931/AR/MSP/DRSTLT/SSDB/ HDB), participants who came for Obstetrics and Gynaecology consultation were approached at the reception before or after their consultation with the attending physician. The study objectives and procedure were explained to them. Interested participants signed the consent form and were enrolled for study. A pretested structured questionnaire was administered to eligible participants. Information collected from participants was: socio-demographic data: age, occupation, level of education, and marital status. The obstetric history included number of pregnancies, outcome of pregnancy, puerperal infections, history of pelvic procedures and duration of trial for a pregnancy. The gynaecological history included: menstrual irregularities, history of STIs, unsafe abortion, pelvic surgeries, uterine fibroids, PCOS, endometriosis and contraceptive use. The sexual history such as frequency of coitus, multiple/new sexual partners was elicited.

The men were asked about a history of mumps, testicular torsion, varicocele, genital injury/swelling, genital surgery and genital infections.

Lifestyle assessment included: alcohol consumption, cigarette smoking, use of recreational drugs, and exposure to chemicals, toxins and radiation.

\section{Data management and analysis}

The data were entered in Microsoft Excel 2013 and exported to the Statistical Package for the Social Sciences (SPSS) version 25 (SPSS, Inc., Chicago, IL, USA). The demographic characteristics and the frequency of reproductive tract infections were summarized using descriptive statistics and the results were displayed in tables. Associations between fertility status, obstetrical, menstrual and coital history were compared in male and female using the student t-test and the Man \&Whitney test. Missing data were coded and not counted in the final analysis. A multivariate logistic regression model was fitted to identify factors associated with infertility in males and females. A p-value $<0.05$ was considered statistically significant.

This study was conducted according to the Helsinki declaration $^{24}$ and reported following the Strobe guidelines for cross-sectional studies.

\section{Results}

During the prospective phase of the study, 370 couples were contacted, and $97.3 \%(360 / 370)$ accepted to participate, and 121 of the 360 participants were diagnosed with infertility.

\section{Prevalence of infertility}

A total of 4732 files were studied in the retrospective phase of the study with 858 cases of infertility while in the prospective phase of study, there were 360 participants of whom, 121 were infertility giving a prevalence of: $858+121 \div 4732+360=979 \div 5092 \times 100=19.23 \%$ 
Table 1: Socio-demographic characteristics of study participants

\begin{tabular}{llll}
\hline Variable & Levels & Male & Female \\
\hline \multirow{4}{*}{ Age group } & Mean age \pm SD & $36.43 \pm 7.5$ & $30.1 \pm 5.7$ \\
& $\mathbf{4 0}$ & $115(31.9)$ & $28(7.8)$ \\
& $\mathbf{2 0 - 2 9}$ & $60(16.7)$ & $167(46.4)$ \\
& $\mathbf{3 0 - 3 9}$ & $185(51.4)$ & $165(45.8)$ \\
\hline \multirow{4}{*}{ Marital status } & Total & $\mathbf{3 6 0}$ & $\mathbf{3 6 0}$ \\
& Cohabiting & $71(19.7)$ & $71(19.7)$ \\
& Married & $220(61.1)$ & $216(60.0)$ \\
& Separated & $4(1.1)$ & $4(1.1)$ \\
& Single & $65(18.1)$ & $69(19.2)$ \\
\hline \multirow{5}{*}{ Profession } & Total & $\mathbf{3 6 0}$ & $\mathbf{3 6 0}$ \\
& Formal & $145(40.3)$ & $98(27.2)$ \\
& Informal & $206(57.2)$ & $96(54.4)$ \\
& Unemployed & $9(2.5)$ & $66(18.3)$ \\
\hline & Total & $\mathbf{3 6 0}$ & $\mathbf{3 6 0}$ \\
\hline
\end{tabular}

As shown in table 1, most study participants were in the Infertile couples were older than fertile couples, were age group 30-39 years with mean age of women being married and their professions were in the informal sec30.1 (SD 5.7) years and that of men 36.4 (SD 7.5) years. tor (self-employment, business, traders etc.).

Table 2: Reproductive health characteristics of study population

\begin{tabular}{|c|c|c|c|c|}
\hline Characteristics & Variable & $\begin{array}{l}\text { Infertile } \\
\text { couples } \\
(\mathrm{N}=121)\end{array}$ & $\begin{array}{l}\text { Fertile } \\
\text { couples } \\
(\mathrm{N}=\mathbf{2 3 9})\end{array}$ & p-value \\
\hline & Menarche in years, mean (SD) & $13.8(1.7)$ & $13.7(1.5)$ & 0.142 \\
\hline \multirow{3}{*}{$\begin{array}{l}\text { Characteristics } \\
\text { of menstrual } \\
\text { cycle }\end{array}$} & Cycle length in days, median (Range) & $28(21-57)$ & $28(21-37)$ & 0.01 \\
\hline & Duration of periods in days, median (range) & $4(2-14)$ & $4(1-14)$ & 0.066 \\
\hline & Age of first coitus in years, mean (SD) & $18.0(2.0)$ & $18.4(2.6)$ & 0.14 \\
\hline \multirow[t]{2}{*}{ Coital history } & Frequency of coitus/week, median (range) & $3(1-7)$ & $2(0-5)$ & 0.001 \\
\hline & Previous pregnancies, median (range) & $2(0-6)$ & $3(1-7)$ & 0.001 \\
\hline \multirow{2}{*}{$\begin{array}{l}\text { Obstetrical } \\
\text { history }\end{array}$} & Previous deliveries, median (range) & $0(0-5)$ & $1(0-6)$ & 0.001 \\
\hline & Number of previous abortions, median (range) & $1(0-3)$ & $0(0-5)$ & 0.001 \\
\hline
\end{tabular}

Note: The tests used here are student's t-test for means and the Man \&Whitney test for median.

The range here gives a better appraisal of the variation in the responses than the interquartile range

Table 2 shows that the median menstrual cycle length in days $(p=0.01)$, frequency of coitus/week, median (range) $(\mathrm{p}=0.001)$, the median number of previous pregnancies $(\mathrm{p}=0.001)$, the median number of previous deliveries $(\mathrm{p}=0.001)$ and the median number of previous abortions $(\mathrm{p}=0.001)$ was different between the fertile and infertile couples. 
Table 3: Male factors associated with infertility in couples in Douala (Multivariable analysis)

\begin{tabular}{lllll}
\hline Variable & Levels & AOR & $\mathbf{9 5 \%}$ CI & p-value \\
\hline \multirow{2}{*}{ Age group } & $30-39$ & 0.30 & $0.17-0.53$ & 0.000 \\
& $20-29$ & 0.06 & $0.02-0.20$ & 0.000 \\
\hline Fathered a child & Yes & 1 & & \\
\hline History of mumps disease & Yo & 0.31 & $0.17-0.57$ & 0.000 \\
& No & 1 & & \\
\hline Erectile dysfunction & Yes & 2.77 & $1.46-5.25$ & 0.002 \\
& No & 1 & & \\
\hline Ejaculation problems & Yes & 4.47 & $1.46-5.25$ & 0.000 \\
\hline Exposure to chemicals/toxic Yes & 1 & & \\
substances/pesticides & No & 3.5 & $0.35-36.24$ & 0.284 \\
\hline Smoking & No & 1 & & \\
\hline
\end{tabular}

AOR: Adjusted odd ratio, CI: Confidence interval

Note: 1. Here we modeled Infertile as the response, treating fertile as the reference category. The model fitted here is a multiple logistic regression model. We have to interpret adjusted odd ratios and confidence intervals.

2. The two Predictors Testicular torsion and History of genital injury did not contribute anything to the model and were excluded from the model.

\section{Factors associated with couple infertility}

As shown in table 3 , male partners in the age groups 20-29 years and 30-39 years and those who had previously fathered a child were less likely to have infertility (AOR 0.09; 95\% CI: 0.03-0.26, $\mathrm{p}=0.000)$, (AOR 0.31; 95\% CI: $0.18-0.54, \mathrm{p}=0.000)$ and (AOR 0.31; 95\% CI:
0.17-0.57, $\mathrm{p}=0.000)$, respectively. Furthermore, male participants with a history of mumps (AOR 2.9; 95\% CI: 1.54-5.46, $\mathrm{p}=0.001$ ), erectile dysfunction (AOR 4.6; 95\% CI: 2.1-10.2, $\mathrm{p}=0.000)$ and exposure to chemicals / toxic substances (pesticides) (AOR 17.4; 95\% CI: 3.198.9, $\mathrm{p}=0.001)$ were more likely to be infertile.

Table 4: Female factors associated with infertility in couples in Douala (Multivariable analysis)

\begin{tabular}{lllll}
\hline Variables & Levels & AOR & 95\% CI & p-value \\
\hline Female age group & $30-39$ & 0.172 & $0.06-0.54$ & 0.003 \\
& $20-29$ & 0.115 & $0.03-0.39$ & 0.000 \\
& $>40$ & 1 & & \\
\hline History of sexually & transmitted Yes & 2.483 & $1.37-4.49$ & 0.003 \\
infection & & & & \\
\hline Pelvic surgery on ovaries & No & 1 & & \\
& Yes & 0.622 & $0.27-1.44$ & 0.268 \\
\hline Uterine fibroids & No & 1 & & \\
\hline Painful menses or dysmenorrhea & Yes & 3.409 & $1.66-7.02$ & 0.001 \\
& No & 1 & & \\
\hline Pain during intercourse or dyspareunia & Yes & 1.955 & $0.90-4.23$ & 0.089 \\
& No & 1 & & \\
\hline Abortion & Yes & 1.889 & $0.99-3.59$ & 0.052 \\
\hline Had more than one sexual partner & Yes & 1.557 & $0.80-3.04$ & 0.194 \\
& No & 1 & & \\
\hline
\end{tabular}

AOR: Adjusted odd ratio, CI: Confidence interval

Note: 1- Here we modeled Infertile as the response, treating fertile as the reference category

2- The variable diagnosis or treatment of endometriosis could not enter the model because of data is dislocated 
Table 4 shows that female participants with a history of reproductive tract infection/STI/PID (AOR 2.4; 95\% CI: $1.34-4.40, \mathrm{p}=0.004)$, those with a history of uterine fibroids (AOR 3.4; 95\% CI: 1.65-7.09, $\mathrm{p}=0.001$ ) those with a history of painful menses or dysmenorrhea
(AOR 2.6; 95\% CI: 1.34-5.18, $\mathrm{p}=0.005$ ) and abortion (AOR 1.9; 95\% CI: 0.99-3.59, $\mathrm{p}=0.05$ ) were more likely to be infertile.

On the other hand female participants who were in the age groups (20-30 years) and (30-39 years) had a 12.5\% and $18 \%$ chance of having infertility.

Table 5: Frequency of reproductive tract infections among couples seeking care for infertility in Douala

\begin{tabular}{|c|c|c|}
\hline Diagnosis & Females, $\mathbf{N}(\%)$ & Males, N (\%) \\
\hline Chlamydia & $78(50.3)$ & $83(53.2)$ \\
\hline Mycoplasma & $19(12.3)$ & $18(11.5)$ \\
\hline Ureaplasma & $14(9.0)$ & $0(0)$ \\
\hline Syphilis & $11(7.1)$ & $13(8.3)$ \\
\hline Gonorrhea & $6(3.9)$ & $28(18.0)$ \\
\hline $\begin{array}{l}\text { Chlamydia and } \\
\text { mycoplasma }\end{array}$ & $11(7.1)$ & $0(0)$ \\
\hline Chlamydia and syphilis & $11(7.1)$ & $11(7.1)$ \\
\hline $\begin{array}{l}\text { Chlamydia and } \\
\text { ureaplasma }\end{array}$ & $5(3.2)$ & $0(0)$ \\
\hline Chlamydia and gonorrhea & $0(0)$ & $2(1.3)$ \\
\hline Gonorrhea and syphilis & $0(0)$ & $1(0.6)$ \\
\hline
\end{tabular}

As shown in table 5 , the most frequent microorganisms found among participants were Chlamydia trachomatis, Mycoplasma hominis and Ureaplasma urealyticum.

\section{Discussion}

This study aimed to determine the prevalence and factors associated with infertility in three hospitals in Douala, Cameroon. The prevalence of infertility was $19.2 \%$. The factors associated with female infertility included a history of RTI, presence of uterine fibroids, dysmenorrhea and abortions, while exposure to chemicals/toxins/pesticides, a history of mumps, and erectile dysfunction was associated with male infertility.

\section{Prevalence of infertility}

It has been previously reported that the burden of in- fertility is more among the low-income countries of sub-Saharan Africa and an infertility belt has been described extending from Angola to the Sudan including Cameroon, Gabon, Nigeria ${ }^{25}$. The reported prevalence of $19.2 \%$ in this study could even be higher because cultural and social barriers impede couples from disclosing fertility problems to healthcare providers. This is consistent with other studies 9, 26,27. The fertility rate in Cameroon has dropped from 6 births per woman in 1966 to 4.8 births per woman in $2015^{28}$. That notwithstanding, the fertility rate for urban towns like Douala and Yaoundé are 3.2 and 3.5 births per woman, respectively ${ }^{28,29}$. This is particularly low compared to other areas in Cameroon with high fertility rates like the Extreme North Region and West Region that have fertility rates of 6.8 and 6.0 births per woman, respectively ${ }^{28,29}$. However, this infertility prevalence was lower than the 
rates reported for other sub-Saharan countries. Sule et al., and Polis CB et al. reported a prevalence of $51.8 \%$ and $31.1 \%$ (95\% CI: $27.9-34.7 \%)^{8,30}$. The difference in prevalence may be due to study setting and the definition of infertility. In our study, we used the WHO definition of infertility as inability to conceive after $\geq 12$ months of regular, unprotected sexual intercourse in a woman of reproductive age (15-49 years) while Sule and Polis used demographic approaches that considered 5-years periods with no births though such long periods may be less clinically relevant. Also, Polis et al. used the current duration (CD) approach technique to estimate a population-level time-to-pregnancy (TTP) distribution and infertility prevalence using a cross-sectional design. This approach samples couples at risk of pregnancy at the time of interview and determines their current length of time-at-risk of pregnancy with the advantage that it is a cost-efficient cross-sectional study design, that also includes all couples at risk of pregnancy regardless of prior fertility history (e.g. childless couples who may be more likely to be infertile) 2 or pregnancy intentions (e.g. couples who may be infertile but have stopped trying) ${ }^{30}$.

\section{Factors associated with couple infertility}

We observed a progressive increase in the prevalence of infertility with advancing age in both males and females. In the couples, the rate of infertility almost doubled with a ten-year increase in ages. The reason for this is that majority of couples in Cameroon seek medical attention for infertility relatively late after failure from traditional medicine/spiritualist. Furthermore, the referral system of patients to appropriate specialists is not well respected. The resultant effect is that, couples waste valuable time consulting ancillary medical staff; nurses, midwives or the general medical practitioners for fear of high cost in specialized centres or distance from specialized centres ${ }^{12}$. Some of them would even want to hide their fertility problems because of cultural beliefs ${ }^{31,32}$. Besides, in women, advanced age is associated with a decrease in the quality and quantity of the oocytes in the ovarian reserves, thus increasing the rate of female infertility ${ }^{33,34}$. In males, despite the continuous sperm production throughout life, testicular function and sperm quality deteriorate with age. In both groups, the offsprings have increased rates of genetic abnormalities and women are prone to miscarriages as a result of advanced ages ${ }^{34,35}$. Therefore, couples with advanced age need counseling regarding the declining fertility rates/potentials of women.

In Cameroon, the pitfalls of infertility management are the inability to diagnose the cause of infertility early. This is related to lack of technical know how in some health facilities or lack of finances on the part of the couples. This is compounded by the fact that health insurance does not cover infertility matters for the small proportion of workers who have health insurance as compared to high-income countries such as Israel, France and Belgium ${ }^{36,37}$. For this reason, medical practitioners are sometimes obliged to use the syndromic approach to diseases (based on association of symptoms and signs) in the management of many medical conditions including infertility in Cameroon ${ }^{38}$.

The female factors independently associated with infertility were: dysmenorrhea or painful menses, uterine fibroids, history of reproductive tract infection/sexually transmitted infections and history of abortions.

Dysmenorrhea was found to be independently associated with infertility. This occurrence may be due to underlying gynaecological problems such as chronic PID and endometriosis. Typically, endometriosis presents with dysmenorrhea, dyspareunia, chronic pelvic pain and infertility. The association of dysmenorrhea and infertility in this study is consistent with previous reports that showed that about 25 to $50 \%$ of infertile women have endometriosis, and 30 to $50 \%$ of women with endometriosis are infertile ${ }^{39}$. However, the diagnosis of endometriosis may be difficult in our environment because syndromic diagnosis by using signs and symptoms may be erroneous because the clinical presentation of endometriosis is variable. The gold standard for the diagnosis of endometriosis is laparoscopy and histopathology of biopsied samples though others have recently suggested clinical diagnosis and optimal medical treatment ${ }^{40}$. There are few centres performing laparoscopic surgery in Cameroon ${ }^{41,42}$. Laparoscopic surgery is practiced only at the DGH among the study hospitals, though not all the gynaecologists at the DGH are proficient in the technique.

The association between menorrhagia, dysmenorrhea, intermenstrual bleeding and infertility in this study may be because a substantial proportion of our participants had uterine fibroids ${ }^{43}$. Multiple uterine fibroids are common among black women, and are associated with infertility ${ }^{44}$. Besides, Cameroon is in an endemic zone for uterine fibroids therefore screening for fibroids among infertile women in Cameroon should be the mainstay ${ }^{12}$. Uterine leiomyoma's are present in approximately $5-10 \%$ of patients presenting with infertility, although independently associated with infertility in only $1 \%$ to $2.4 \%$ of the infertile patients ${ }^{45}$, 46 . Okogbo 
et al. 2011 in South West Nigeria reported that 47.7\% of menstrual irregularities and $31.9 \%$ of infertility cases were due to uterine leiomyoma's ${ }^{47}$.

Reproductive tract infection or pelvic inflammatory disease (PID) is a common cause of hospitalization in most hospitals in Cameroon and other countries in sub-Saharan Africa. There is a direct correlation or risk association between Chlamydia trachomatis infection, PID and tubal infertility ${ }^{12,48,49}$. However, another study in Cameroon reported that Mycoplasma species occurred more frequently than $C$. trachomatis in their study ${ }^{50}$.

Abortion as a risk factor for female infertility is related to secondary infertility. Besides, the practice of voluntary induced abortion is illegal in Cameroon except for therapeutic abortions where the pregnancy could compromise or jeopardize maternal or foetal outcomes. This has led to increased complications from abortions performed by unqualified medical and non-medical staff thereby increasing the maternal morbidity from post-abortion infections (endometritis), uterine synechiae, infertility and death ${ }^{12,51,52}$.

The factors associated with male infertility in this study were: erectile dysfunction, exposure to chemicals/toxins, and history of mumps. Cigarette smoking affected the fertility of participants in this study though it was not statistically significant (AOR 2.65; 95\% CI: 0.927.62, $\mathrm{p}=0.07$ ).

In Cameroon, male factor infertility is a very difficult problem to handle because culturally, infertility is considered a female problem and women usually take the blame for not being able to procreate ${ }^{53}$. As long as a man has full erection he will hardly accept that he is infertile despite being diagnosed with low sperm count ${ }^{53}$. Exposure to toxins/chemicals is an important finding in this study. Cameroon is a country that thrives more on agriculture. There are companies that grow banana in Tiko, Nyombe, Penja and Palms in Bomono and Limbe. These are all feeder localities to health facilities in Douala. The companies in these localities usually spray their plantations using small aircrafts. The local farmers who do subsistence farming also spray their farms with pesticides and/or herbicides using manual pumps. The effect of these chemicals on the fertility of this population has not been studied. However, several studies based on exposure to environmental toxins suggest a negative impact on semen quality, in terms of sperm concentration, motility, and/or morphology. These toxins may exert estrogenic and/or anti-androgenic effects, which in turn alter the hypothalamic-pituitary-gonadal axis (HPGA), induce sperm DNA damage, or cause sperm epigenetic changes ${ }^{17}$. Besides, others have reported a $7.4 \%$ prevalence of primary infertility among farm workers exposed to pesticide ${ }^{54}$. In Cameroon, mumps usually occurs during childhood and people do not associate the condition with infertility. However, it has been reported that mumps orchitis is associated with asthenospermia (poor sperm motility), and infertility in 30-87\% patients with bilateral mumps orchitis ${ }^{55}$.

Most men who will readily seek medical attention in Cameroon are those with erectile dysfunction (inability to have or sustain a good quality erection) (ED) and advancing male age has been associated with $\mathrm{ED}^{35}$. Some of these men will take to alcohol and cigarette smoking thereby complicating the condition. High levels of alcohol intake do appear to be associated with changes in semen that may affect fertility. This is consistent with studies that have reported that cigarette smoking has a dose-dependent association with endothlial disease leading to erectile dysfunction and that this effect is observed more with more than 20-pack years of exposure. Cessation of smoking improves penile tumescence and rigidity ${ }^{56-58}$.

More so, others have reported that smoking was associated with reductions in semen quality including sperm concentration, motility and morphology ${ }^{59,60}$. Harlev et al in South Africa reported a well-established biological finding that smoking increases the presence of reactive oxygen species, thereby resulting in oxidative stress (OS). OS has devastating effects on sperm parameters, such as viability and morphology, and impairs sperm function, hence reducing male fertility ${ }^{14}$. Haifa reported that $38 \%$ of the infertile males who were smokers had low levels of reproductive hormones and semen parameters compared to non-smokers ${ }^{61}$.

\section{Study limitations and strengths}

The participants of the interview could have had recall bias of some information that could be considered private. We did not study the link between erectile dysfunction and cigarette smoking. The results obtained from this study may not represent what obtains in other parts of Cameroon because of cultural differences. Finally, the cross-sectional nature of the study could not allow for causal inference and sampling may be biased since it is not a probability sampling.

This is one of the few studies regarding infertility and its associated factors in Cameroon. This should open the way for other studies.

\section{Conclusion}

One in every five couples in this study is infertile. The 
factors associated with female infertility include a history of reproductive tract infections, presence of uterine fibroids, dysmenorrhea and abortions while exposure to chemicals/toxins or pesticides, a history of mumps, and erectile dysfunction was associated with male infertility. We recommend that reproductive health education (abortion care etc.) and screening programs for sexually transmitted infections (Chlamydia trachomatis, Mycoplasma and Neisseria gonorrhea) should be offered readily to couples by healthcare providers.

\section{Acknowledgements}

We are grateful to the medical and nursing staff of the study hospitals for the assistance they gave us during the study.

\section{Competing interests}

The authors declare that they have no competing interests.

\section{Funding}

None

\section{Author's contribution}

TOE, CNM and ET conceptualized the study and wrote the submitted version of the manuscript. CNM did the data collection ET and NT analyzed the data. EBP read and approved the submitted version of the manuscript. All the authors read and approved the final submitted version of the manuscript.

\section{References}

1. Vander Borght M, Wyns C. Fertility and infertility: Definition and epidemiology. Clin Biochem. 2018; 62:210 PubMed.

2. Zegers-Hochschild F, Adamson GD, Dyer S, Racowsky C, de Mouzon J, Sokol R, et al. The international glossary on infertility and fertility care, 2017. Hum Reprod. 2017; 32:1786-801 PubMed.

3. Oyeniran AA, Bello FA, Oluborode B, Awowole I, Loto OM, Irinyenikan TA, et al. Narratives of women presenting with abortion complications in Southwestern Nigeria: A qualitative study. PloS One. 2019; 14.

4. Leke RJ. Reducing Maternal Mortality Through the Prevention of Unsafe Abortion and Their Complications in Cameroon. Int J Gynecol Clin Pract. 2018.

5. Bongaarts J, Casterline J. Fertility Transition: Is sub-Saharan Africa Different? Popul Dev Rev. 2013; 38:153-68 PubMed.

6. Menuba IE, Ugwu EO, Obi SN, Lawani LO, Onwuka CI. Clinical management and therapeutic outcome of infertile couples in southeast Nigeria. Ther Clin Risk Manag. 2014; 10:763.

7. Direkvand-Moghadam A, Sayehmiri K, Delpisheh A. The global trend of infertility: an original review and meta-analysis. Int J Epidemiol Res. 2014; 1:35-43 PubMed.

8. Sule JO, Erigbali P, Eruom L. Prevalence of infertility in women in a southwestern Nigerian community. Afr J Biomed Res. 2008; 11: 225-7 PubMed.

9. Panti AA, Sununu YT. The profile of infertility in a teaching Hospital in North West Nigeria. Sabel Med J. 2014; $17: 7$.

10. Deshpande PS, Gupta AS. Causes and prevalence of factors causing infertility in a public health facility. $J$ Hum Reprod Sci. 2019; 12:287.

11. Unuane D, Tournaye H, Velkeniers B, Poppe K. Endocrine disorders \& female infertility. Best Pract Res Clin Endocrinol Metab. 2011; 25:861-73.

12. Egbe TO, Nana-Njamen T, Elong F, Tchounzou R, Simo AG, Nzeuga GP, et al. Risk factors of tubal infertility in a tertiary hospital in a low-resource setting: a case-control study. Fertil Res Pract. 2020; 6:3.

13. Xuan L, Liu X, Wang J. A Study on Risk Factors and Etiology of Female Infertility. International Conference on Medicine, Biology, Materials and Manufacturing. 2018: 1-4.

14. Harlev A, Agarwal A, Gunes SO, Shetty A, du Plessis SS. Smoking and male infertility: an evidence-based review. World J Mens Health. 2015; 33:143-60 PubMed.

15. Agarwal A, Mulgund A, Hamada A, Chyatte MR. A unique view on male infertility around the globe. Reprod Biol Endocrinol. 2015; 13:37.

16. Ring JD, Lwin AA, Köhler TS. Current medical management of endocrine-related male infertility. Asian J Androl. 2016; 18:357.

17. Mima M, Greenwald D, Ohlander S. Environmental toxins and male fertility. Curr Urol Rep. 2018; 19:50.

18. Gul S, Ashraf H, Khawar O, Moid M. Prevalence and Preventive Measures of Infertility in Male by Kruger's Criteria, a Randomized Study in Private and Government Health Care Hospitals. Bangladesh J Med Sci. 2019; 18:94-9 PubMed.

19. Sengupta P, Nwagha U, Dutta S, Krajewska-Kulak E, Izuka E. Evidence for decreasing sperm count in African population from 1965 to 2015. Afr Health Sci. 2017; 17:418-27 PubMed.

20. Okutman O, Muller J, Skory V, Garnier JM, Gaucherot A, Baert Y, et al. A no-stop mutation in MAGEB4 is a possible cause of rare $\mathrm{X}$-linked azoospermia and oligozoospermia in a consanguineous Turkish family. $J$ Assist Reprod Genet. 2017; 34:683-94.

21. Yıldırım Y, Ouriachi T, Woehlbier U, Ouahioune W, 
Balkan M, Malik S, et al. Linked homozygous BMPR1B and PDHA2 variants in a consanguineous family with complex digit malformation and male infertility. Eur J Hum Genet. 2018; 26:876-85 PubMed.

22. Ma Y, Xie N, Xie D, Sun L, Li S, Li P, et al. A novel homozygous FBXO43 mutation associated with male infertility and teratozoospermia in a consanguineous Chinese family. Fertil Steril. 2019; 111:909-17 PubMed.

23. Eng J. Sample size estimation: how many individuals should be studied? Radiology. 2003; 227:309-13 PubMed.

24. Association GA of the WM. World Medical Association Declaration of Helsinki: ethical principles for medical research involving human subjects. $\mathrm{J} \mathrm{Am}$ Coll Dent. 2014; 81:14.

25. Nachtigall RD. International disparities in access to infertility services. Fertil Steril. 2006; 85:871-5 PubMed. 26. Kumar D. Prevalence of female infertility and its socio-economic factors in tribal communities of Central India. 2007; 7: 456

27. Nwajiaku LA, Mbachu II, Ikeako L. Prevalence, Clinical Pattern and Major Causes of Male Infertility in Nnewi, South East Nigeria: A Five Year Review. Afrimedic J. 2012; 3:16-9 PubMed.

28. Cameroun Taux de fertilité, 1960-2017 - knoema. com. Knoema. https://knoema.fr//atlas/Cameroun/ Taux-de-fertilité. Accessed 6 Feb 2018.

29. INS/Cameroun IN de la S-, International ICF. Cameroun Enquête Démographique et de Santé et à Indicateurs Multiples (EDS-MICS) 2011. 2012. https://dhsprogram.com/publications/publication-FR260-DHS-Final-Reports.cfm. Accessed 1 Sep 2019.

30. Polis CB, Cox CM, Tunçalp Ö, McLain AC, Thoma ME. Estimating infertility prevalence in low-to-middleincome countries: an application of a current duration approach to Demographic and Health Survey data. Hum Reprod. 2017; 32:1064-74 PubMed.

31. Ombelet W, Cooke I, Dyer S, Serour G, Devroey P. Infertility and the provision of infertility medical services in developing countries. Hum Reprod Update. 2008; 14:605-21 PubMed.

32. Ombelet W, Campo R. Affordable IVF for developing countries. Reprod Biomed. 2007; 15:257-65 PubMed. 33. Liu K, Case A, Cheung AP, Sierra S, AlAsiri S, Carranza-Mamane $\mathrm{B}$, et al. Advanced reproductive age and fertility. J Obstet Gynaecol Can. 2011; 33:1165-75.

34. Abbas HA, Rafei RE, Charafeddine L, Yunis K. Effects of Advanced Paternal Age on Reproduction and Outcomes in Offspring. Neo Reviews. 2015; 16:e69-83.

35. Harris ID, Fronczak C, Roth L, Meacham RB. Fertility and the aging male. Rev Urol. 2011; 13:e184.
36. Egbe TO, Wafo CY, Bollo BB, Pany C, Onomo MJ, Sandjon G. Successful pregnancy with donor eggs in-vitro fertilization after premature ovarian insufficiency in a tertiary hospital in a low-income setting: a case report. Fertil Res Pract. 2016; 2:12.

37. Ory SJ, Devroey P, Banker M, Brinsden P, Buster J, Fiadjoe M, et al. International Federation of Fertility Societies Surveillance 2013: preface and conclusions. Fertil Steril. 2014; 101:1582-3 PubMed.

38. Vuylsteke B. Current status of syndromic management of sexually transmitted infections in developing countries. The Medical Society for the Study of Venereal Disease; 2004.

39. Holoch KJ, Lessey BA. Endometriosis and infertility. Clin Obstet Gynecol. 2010; 53:429-38 PubMed.

40. Taylor HS. Clinical diagnosis of endometriosis and optimal medical therapy. Fertil Steril. 2017; 108:759-60 PubMed.

41. Egbe TO, Enow-Orock GE, Halle Ekane GE, Tchente $\mathrm{CN}$, Belley-Priso E. Laparoscopic Myomectomy in a Tertiary Care Centre in Douala, Cameroon. Journal of Advances in Medicine and Medical Research, 2016; 13(7): 1-10.

42. Kasia JM, Ngowa JDK, Mimboe YS, Toukam M, Ngassam A, Noa CC, et al. Laparoscopic Fimbrioplasty and Neosalpingostomy in Female Infertility: A Review of 402 Cases at the Gynecological Endoscopic Surgery and Human Reproductive Teaching Hospital in Yaoundé-Cameroon. J Reprod Infertil. 2016; 17:104-9 PubMed.

43. Ciavattini A, Clemente N, Delli Carpini G, Di Giuseppe J, Giannubilo SR, Tranquilli AL. Number and size of uterine fibroids and obstetric outcomes. J Matern-Fetal Neonatal Med Off J Eur Assoc Perinat Med Fed Asia Ocean Perinat Soc Int Soc Perinat Obstet. 2015; 28:4848.

44. Gupta S, Jose J, Manyonda I. Clinical presentation of fibroids. Best Pract Res Clin Obstet Gynaecol. 2008; 22:615-26.

45. Desai P, Patel P. Fibroids, infertility and laparoscopic myomectomy. J Gynecol Endosc Surg. 2011; 2:36-42.

46. Brady PC, Stanic AK, Styer AK. Uterine fibroids and subfertility: an update on the role of myomectomy. Curr Opin Obstet Gynecol. 2013; 25:255-9 PubMed.

47. Okogbo FO, Ezechi OC, Loto OM, Ezeobi PM. Uterine Leiomyomata in South Western Nigeria: a clinical study of presentations and management outcome. Afr Health Sci. 2011; 11:271-8 PubMed.

48. Ojule JD, Ibe VC, Theophilus JC. Chlamydia Trachomatis Infection and Tubal Infertility in Port Harcourt, Southern, Nigeria. West Afr J Med. 2015; 34:83-8 PubMed. 
49. Olaleye O, Olamijulo JA. The value of chlamydial antibody level for predicting tubal blockage among women undergoing hysterosalpingography in Lagos, Nigeria. Int J Gynaecol Obstet Off Organ Int Fed Gynaecol Obstet. 2016; 134:33-6.

50. Nkwabong E, Dingom MAN. Acute Pelvic Inflammatory Disease in Cameroon: A Cross Sectional Descriptive Study. Afr J Reprod Health. 2015; 19:87-91 PubMed.

51. Egbe T, Dingana T, Halle-Ekane G, Atashili J, Nasah B. Determinants of Maternal Mortality in Mezam Division in the North West Region of Cameroon: A Community-based Case Control Study. Int J Trop Dis Health. 2016; 15:1-15.

52. Ekane GEH, Obinchemti TE, Tchente CN, Fokunang LK, Njamen TN, Bechem NN, et al. Attainment of the fifth millennium development goal: utopia or reality based on trends in maternal mortality in 12 years in two regional hospitals in fako division, Cameroon? A retrospective study. Open J Obstet Gynecol. 2014; 4:771.

53. Feldman-Savelsberg P. Plundered kitchens and empty wombs: fear of infertility in the Cameroonian grassfields. Soc Sci Med. 1994; 39:463-74 PubMed.

54. Neghab M, Momenbella-Fard M, Naziaghdam R, Salahshour N, Kazemi M, Alipour H. The effects of exposure to pesticides on the fecundity status of farm workers resident in a rural region of Fars province, southern Iran. Asian Pac J Trop Biomed. 2014; 4:324-8.

55. Davis NF, McGuire BB, Mahon JA, Smyth AE, O'Malley KJ, Fitzpatrick JM. The increasing incidence of mumps orchitis: a comprehensive review. BJU Int. 2010; 105:1060-5 PubMed.

56. Ricci E, Beitawi SA, Cipriani S, Candiani M, Chiaffarino F, Viganò P, et al. Semen quality and alcohol intake: a systematic review and meta-analysis. Reprod Biomed Online. 2017; 34:38-47.

57. Kovac JR, Khanna A, Lipshultz LI. The effects of cigarette smoking on male fertility. Postgrad Med. 2015; 127:338-41 PubMed.

58. DeLay KJ, Haney N, Hellstrom WJ. Modifying risk factors in the management of erectile dysfunction: a review. World J Mens Health. 2016; 34:89-100 PubMed.

59. Meri ZB, Irshid IB, Migdadi M, Irshid AB, Mhanna SA. Does cigarette smoking affect seminal fluid parameters? A comparative study. Oman Med J. 2013; 28:12. 60. El-Melegy NT, Ali M-EM. Apoptotic markers in semen of infertile men: association with cigarette smoking. Int Braz J Urol. 2011; 37:495-506 PubMed.

61. Al-Turki HA. Effect of smoking on reproductive hormones and semen parameters of infertile Saudi Arabians. Urol Ann. 2015; 7:63. 